Von Schomberg, René (2019). 'Why Responsible Innovation' in: The International

Handbook on Responsible Innovation. A Global Resource. Von Schomberg, René and J. Hankins (Eds.). Cheltenham and Northampton: Edward Elgar Publishing. pp.12-32

\title{
Why Responsible Innovation?
}

\section{René von Schomberg ${ }^{1}$}

Below I will provide a bird's eye view on six deficits in the global research and innovations system that constitute obstacles for innovations delivering on societal desirable objectives, describing how we got where we are and pointing the way forward. I will first give a short historical account of the progress we have achieved in the governance of the risks of emerging technologies, then highlight six departure points for a vision of responsible innovation based upon reflections on the six deficits in the research and innovation system

Nuclear power plants were regularly erected during the 1950s and 1960s with very little interference from our democratic institutions (contracts with nuclear technology operators were not made accessible with a view to protection of intellectual property rights). This occurred in absence of professional risk governance and management, and in a culture of technological optimism: it was not until the early 1970s, decades after the introduction of civil nuclear technology, that it was acknowledged that there were no solutions for the storage of nuclear waste. The institutionalisation of risk identification and analysis as a distinct professional activity, executed by professionals who were not themselves part of the development of technology, and therefore unbiased, emerged only at the end of the 1960s (Evers, Nowotny 1987).

The governance and introduction of subsequent emerging technologies became gradually more comprehensive, however, with most progress achieved in the area of risk governance. In Europe, regulations and directives were put in place prior to the introduction of genetically modified organisms in the 1990s, as well as for particular food products involving nanotechnology. The learning process in defining and managing risks also took account of an ever-evolving public debate, not in the least, and prominently, during responses to crisis. In Europe, the BSE (Bovine spongiform encephalopathy) and other food crises brought about a major overhaul of risk governing and management mechanisms and led to changes in several areas, including:

how scientific advice was made,

the choice of the composition of scientific advisory bodies,

the transparency of the decision-process and

the adoption of the precautionary principle in the policy making process as part of the broader issue of European Governance. (Commission of the European Communities, 2001).

The diagnosis from the European Commission at that time was:

The advent of bio-technologies are highlighting the unprecedented moral and ethical issues thrown up by technology. This underlines the need for a wide range of disciplines and experience beyond the purely scientific

Recent food crises have highlighted the importance of informing people and policy makers about what is known and where uncertainty persists. But they have also undermined public confidence in expert-based policy-making. Public perceptions are 
not helped by the opacity of the Union's system of expert committees or the lack of information about how they work. It is often unclear who is actually deciding - experts or those with political authority. At the same time, a better-informed public increasingly questions the content and independence of the expert advice that is given" (page 18).

The formation of public opinion on new technologies is not a historically or geographically isolated process; rather, it is inevitably linked to prior (national and international) debate on similar topics. Ideally, such debates should enable a learning process - one that allows for the fact that public opinion forms within particular cultures and political systems. It is therefore not surprising that, for example in the case of nanotechnologies, the nature of public debate and its role in the policy making process is articulated against a background of previous discussion of the introduction of new technologies, or that specific national experiences with those technologies become important. In particular, the introduction of genetically modified organisms (GMOs) into the environment is an important reference point within Europe (but frequently absent in such debates in the USA). This historical development of policy frameworks can be followed through the ways in which terms are used and defined: initially, definitions are often determined by the use of analogies that, in the initial stages of the policy process, serve to 'normalise' new phenomena. In a number of countries, for instance, GMOs were initially regulated through laws that deal with toxic substances. Subsequently such analogies tend to lose their force as scientific insight into technology grows and distinct regulatory responses can be made. GMOs, for example, eventually became internationally defined as 'potentially hazardous', with a case by case approach adopted in the European Union under new forms of precautionary regulation. This framework was developed over a period of decades, and thereby considered the ever-widening realm in which GMOs could have effect (developing from an exclusive focus on direct effects to eventually include indirect and long-term effects). It is not, however, solely the scientific validity of analogies that determines definitions and policy: public interest also plays an important role. Carbon dioxide, for instance, has changed from being viewed as a gas essential to life on earth to being viewed as a 'pollutant'. (This latest iteration of this evolution came just prior to the Copenhagen summit on climate change in December 2009, when the US Environmental Protection Agency defined greenhouse gases as a "threat to public health" - a definition that has important implications for future policy measures, despite having been downplayed again during the Trump administration).

In the case of nanotechnology policy, it seems likely that we are still in the early phases of development. Nanoparticles continue to be defined as "chemical substances" under the European regulatory framework REACH. (Analogies are also made with asbestos, as a way to grasp hold of possible environmental and human health effects, but these are contested. There is no certainty that they will become the definitive way to frame risk assessments).

Nanotechnology in food did not start its public and policy life with a historically blank canvas but has been defined as a 'novel food' under the European Union Novel Foods regulation, which came into existence for the regulation of foods containing GMOs.

\section{First Deficit: Exclusive focus on risk and safety issues concerning new technologies under governmental regulations}

Although the progress in policy frameworks and mechanisms for risk management and governance may look impressive, it came along with an unchanged scope of the responsibility 
of democratic states for emerging technologies. The so-called market hurdles for product authorisations define state responsibilities in terms of safety, quality or efficacy of products. In some specific situations, such as with pharmaceutical products, this may be extended to cost-effectiveness considerations. However, the focus on product-authorisation and the main three aspects noted above involves a technology-neutral approach and an exclusive focus on the safety and quality features of products. The state takes responsibility for the risks of products derived from new technologies, while the benefits are delegated to the 'market' and defined in terms of success within the market. This sharply contrasts with technology-specific research and innovation funding whereby emerging technologies are stimulated with a view to increase the innovation capacity and competitiveness on the one hand and public debate often focussed on the (non-)social desirability of particular outcomes of those technologies beyond their technical risks on the other. Whereas public debates on the societal desirability of outcomes do not have a specific entry point in governmental policy making, specific economic considerations drive the public and private funding of research and innovation actions. A first departure point for a vision of responsible innovation is therefore to advance governance mechanisms that could drive innovations to societally desirable ends. In other words, instead of an exclusive focus on the risks of new technologies, the question of directing or redirecting research and innovation towards societally desirable ends has to be given importance in research and innovation programmes. This implies that we not only have to have professional bodies for risk assessment but also professional bodies that should look into the type of outcomes we want to get out of research and innovation processes, and the establishment of governance mechanisms that should give some direction to -- or steer -- the innovation process. I will make a proposal related to this issue in the final section of this chapter on the sixth deficit.

\section{Second Deficit: Market deficits in delivering on societal desirable innovations}

Innovations often overwhelm people, and virtually no new transformative technological innovations have been predicted in advance. Even at the early stage of technology development, such as in the case of nanotechnology, the first marketed products were not of the kind experts initially predicted. The first products involving nanotechnology were cosmetics, despite expectations centring on healthcare and environmentally sound applications. Although new technologies are generally hyped in their beginning phases, with high expectations on outcomes (such as 'nanobots' that are capable of cleaning our arteries), alongside economic benefits, the reality kicks in with disappointing products such as nano socks that you don't need to wash for a couple of weeks or teddy bears for children that remain equally hygienic for long term use.

There seems to be a general mis-match between the pace of 'new' products entering the market and the societal significance of those products. Notably in areas where our innovation system relies on a handful of multinational companies such in the medical and agrobusiness fields, innovations are not delivering on societal expectations. In the pharmaceutical field, the economic rationale results in counter intuitive research and innovation priorities in the private sector: medicines that can treat rather than cure chronic diseases are preferable from an economic point of view. Malaria, the disease that infects the most victims worldwide, is under-investigated, since the introduction to the market of medicines for the treatment of diseases in top-income countries is economically more beneficial. For Malaria, to a significant extent we rely on the input of philanthropy, such as the Melinda and Bill Gates Foundation, which invests more in combatting Malaria than any other public body in a context where drug makers have abandoned the field. But even high-income countries such as the Netherlands are 
not free from unwanted market- impacts: the country suffers from increasing shortages of medicine supply as drug makers consider it to be a too small market with relative low drugs prices.

Jack Stilgoe (2014) reported in the Guardian that "only 10\% of the world's health research funding goes to $90 \%$ of the world's disease burden. Thomson Reuters found that the disparity is even more stark when we consider published research. The number of papers on elephantiasis and intestinal worms, which together affect more than a billion people, is less than a tenth of the figure for diabetes and HIV/AIDS.".

The international regime for Intellectual Property Rights is at the heart of inhibiting responsible innovation. The Nobel Prize winner Stieglitz made the following diagnosis of the system in a co-authored recent report:

Nowadays, it is widely recognized that the management of innovation in countries like the US has been sub-optimal and led to a situation that is increasingly litigious and plagued by conflicts. In fields such as information technology, a whole set of weak patents and an epidemic of over-patenting has made subsequent innovation difficult and has eroded some of the gains from knowledge creation (see Bessen and Meurer, 2008 among others). Moreover, in some areas, such as in pharmaceuticals, everstronger IP protections has not necessarily led to an increase in the discovery of new chemical entities (see Dosi and Stiglitz, 2014). Rather, the demands and needs of different industries become more opposed, leading to serious concerns for policy makers. There is a shrinking of the knowledge commons as even publicly funded and promoted innovation is privatized, thereby reducing both equity and efficiency (Baker et al., 2017).

Although market-innovations are very effective when they concern efficiency gains as they immediately reflect an economic rationale that honours better outcomes for lower costs, we cannot expect innovations to come equally quickly to the market when they require transformative changes, such as a change of infrastructure, which will not come about without heavy public investment. A second departure point for a vision of responsible innovation is therefore to compensate for existing market deficits and allocate new governance roles for public bodies and stakeholders. The deficit of markets is immediately linked to a further articulation of this deficit: the non-alignment of innovations with broadly shared public values in specific innovation contexts where transformative change has become societally desirable, virtually across all topics touching on sustainable development and / or issues that are dependent on a knowledge commons.

\section{Third deficit: Aligning innovation with broadly shared public values and expectations}

Under the European Framework programme for Research and Innovation Horizon 2020, a number of 'Grand Societal Challenges' have been defined, which followed the call in the Lund Declaration for a Europe that 'must focus on the Grand Societal Challenges of our time' (Lund Declaration 2009 during the Swedish EU presidency). Sustainable solutions are sought in areas such as "global warming, tightening supplies of energy, water and food, ageing societies, public health, pandemics and security (ibid, p.1). 
Arguably, the Grand Societal Challenges of our time reflect a number of normative anchor points of the Treaty in relation to the 'promotion of scientific and technological advance' and which thus can be seen as legitimate. However, the promotion of scientific and technological advance has until now served as a goal in itself. The promotion of scientific and technological advance has not been coupled to other, all interrelated, normative anchor points such as 'ensuring a high level of protection' that, 'sustainable development', 'competitive social market economy' that drive all other EU policies. It does not require much political initiative to couple the promotion of scientific and technological advance with all other major normative anchor points in the EU treaty to give a broader base for the justification of research and innovation beyond assumed economic benefits and increase of competitiveness.

The Lund Declaration states that in order to be responsive the European Research Area must develop 'processes for the identification of Grand Societal Challenges, which gain political support and gradually move away from the current thematic approaches, towards a structure where research priorities are based on these Grand Societal Challenges'. It hopes to give direction to research and innovation in the form of 'broad areas of issue-oriented research in relevant fields' (ibid, p.1). It calls for (amongst other things), broad stakeholder involvement and the establishment of public-private partnerships.

The macro-economic justification for investment in research and innovation emphasizes that innovation is the "only answer" to tackle societal challenges: "Returning to growth and higher levels of employment, combating climate change and moving towards a low-carbon society" (Commission of the European Communities, 2011, p. 3). This approach implicitly assumes that access to and availability of finance for research and innovation will automatically lead to the creations of jobs and economic growth, thereby taking on the societal challenges along the way. The more innovation, the better. The faster it becomes available, the better. In this macro-economic model, innovation is assumed to be rudderless but inherently good, since it produces prosperity and jobs and meets societal challenges addressed through marketdemand.

The Lund Declaration gives, however, an alternative justification for investing in research and innovation, primarily framing this in terms of responding to societal Grand Societal Challenges and further stating that "meeting the Grand Societal Challenges will be a prerequisite for continued economic growth and for improved chances to tackle key issues" (Lund Declaration 2009, p.2). Here, the assumption is that sustainable economic growth is only possible when particular societal objectives are met, in the form of responding to Grand Societal Challenges. Innovation is neither seen as rudderless nor as inherently good. Economic prosperity and the anticipation that innovation yields positive anticipated impacts (such as the creation of jobs and growth) become dependent upon the social context. The Lund Declaration points out that measures are "needed to maximize the economic and societal impact of new knowledge" (ibid., p.2; italics by the author). The idea is clear; to steer the innovation process towards socially beneficial objectives.

Additional measures that go beyond removing barriers for research and innovation such as the availability of and access to finance for research and innovation then become necessary. The Lund Declaration defines a type of justification of investment in research and innovation towards particular positive outcomes. The Lund Declaration underlines a justification of research and innovation beyond economic terms. The question on how to define positive outcomes or "the right impacts" of innovation can be found in the normative anchor points in basic treaties and constitutions. This also brings an advantage for democratic governance: 
organisations and citizen can claim the proper implementation of policies by articulating the meaning of these anchor points in concrete situations. This enabled for example, the citizen organisation Urgenda in the Netherlands to sue the state for negligence in court for not taking appropriate measures for combatting climate change. The Court of Appeal based its ruling on the State's legal duty to ensure the protection of the lives and family life of citizens, also in the long term. This legal duty is enshrined in the European Convention of Human Rights (ECHR), (Urgenda, 2018).

The third departure point for a vision of Responsible innovation marks the paradigm shift from a justification in purely macro-economic terms of publicly funded research and innovation towards a justification of the purpose and direction of innovation in terms of broadly shared pubic values.

\section{Fourth deficit: A focus on the responsible development of technology and technological potentials rather than on responsible innovation.}

The institutional and societal learning processes brought by the introduction of new technologies since World War II have culminated in specific large-scale initiatives to promote the "responsible development" of new technologies under public policy. Nanoscience and nanotechnologies constitute the first historic case in which a technology, in its infancy, is being addressed by such large-scale, multi-billion dollar/euro, mid- to long-term programmes on both sides of the Atlantic. Since 2001, The National Nanotechnology Initiative (2001) has been the U.S. Federal Government's interagency programme for coordinating research and development and enhancing communication and collaborative activities in nanoscale science, engineering, and technology. Support for "responsible development of nanotechnology" features among its major goals (National Nanotechnology Initiative 2001). The European Commission also adopted a European strategy and action plan that emphasized the 'integrated, safe, and responsible' development of nanosciences and nanotechnologies (Commission of the European Communities, 2009, p.10. The 'responsible development of nanotechnology' was under both the American and the European initiative addressed by:

- Identification and management of ethical, legal, and societal implications

- Incorporation of safety evaluation of nanomaterial into the product life cycle and allocation of budgets for identification and study of risks

- Identification of knowledge gaps and regulatory needs

- Involvement of stakeholders and engagement in international dialogue

Reflections on an appropriate governance framework for the responsible development of technologies have led to the call for specific requirements of such a governance process, which shift the focus to the innovation process as such and disconnects from the prior sole focus on exploring technological potential:

- Anticipatory governance: An adequate governance framework should anticipate the intended and unintended impacts of new technologies in economic, environmental, social, and ethical terms. This requires extensive use of technology foresight and technology assessment (Karinen/Guston, 2010).

- Deliberative governance: This implies inclusive governance, one based on broad stakeholder involvement and early public intervention in research and development leading to responsive public policies (Owen et al. 2013) or even a required commitment 
of stakeholders with a view on particular socially desirable outcomes (Von Schomberg 2013).

- An ethics of co-responsibility: The outcomes of research and innovation are the result of institutional and collective actions which often lead to consequences which can hardly be traced back to the actions or intentions of any individual. Societal actors and innovators have to assume shared responsibility for both the intended and unintended outcomes (Von Schomberg 2007).

- The systematic use of normative principles for the design of technologies. Ethics becomes a driving force for innovation rather than a constraint. "Privacy by Design" is the most prominent example of such a normative principle, and Stahl (2011) and others have used this and other principles for devising a responsible governance of information and communication technology (ICT).

- Whenever appropriate, the integration of social science and humanities within interdisciplinary research practices to increase reflexivity (Fisher et al. 2006).

However, responsible innovation has been articulated not only with a view on the anticipation and good management of possible risks of new technologies and their technological potential but also with a view on the 'right impacts of research and innovation'. In other words: what do we want to get out of (publicly) funded research and innovation? In the European Union this has been articulated by a call to direct research and innovation towards the Grand Societal Challenges of our times: climate change, food security, ageing populations, etc. Even more broadly formulated, responsible innovation can be seen to be responsive to basic public values or benefits for humanity (Ozolina et al. 2012) or fundamental rights or the constitutional normative anchor points I outlined above, thus driving innovations towards socially desirable outcomes.

I have proposed the following definition consistent with an ambitious vision of innovation governance:

'Responsible innovation' is a transparent, interactive process by which societal actors and innovators become mutually responsive to each other regarding the ethical acceptability, sustainability and social desirability of the innovation process and its marketable products (Von Schomberg 2013, p.63).

'Responsible research and innovation' shift the focus from research and development of particular technologies and/or particular risks towards the whole innovation process, and its governance which is neither technology-specific, nor solely risk-focused' (ibid., p. $63)$.

Some European Innovation Partnerships, for instance the partnership on 'Healthy Ageing', implicitly seem to practise responsible innovation to the extent that a socially desirable objective (in this case, the increase of life-expectancy by 2 years in 2020) is pursued with multi-optional technological means, as well as by means of social innovation, having public and private bodies committed to overall-normative objectives within flexible and adaptable research and innovation trajectories.

A fourth departure point for a vision of responsible innovation marks thus the shift from an exclusive focus on the development of technologies and their technological potential to the outcomes and management of an innovation process with a view to align innovation with broadly shared public values and expectations. In the context of responsible innovation, the setting of societal objectives takes precedence over the maximisation of the technological potential. 


\section{Fifth deficit: A lack of Open research systems and open scholarship as a necessary, but not sufficient condition for responsible innovation}

Open research and scholarship gradually evolved from two global trends: Open Access to research outputs and Open Source. The former refers to online, peer-reviewed scholarly outputs, which are free to read, with limited or no copyright and licensing restrictions, while Open Source refers to software co-created without any proprietary restriction and which can be accessed and used.

The Budapest Open Access Initiative of 2002 established Open Access for the first time as an internationally desirable publishing practice. Although Open Access became primarily associated with a particular publishing or scientific dissemination practice, the Budapest Open Access Initiative already sought to induce a broader practice of open scholarship that includes the general re-use of all kinds of research products, not just publications or data. But it is only more recently that various forms of open scholarship have evolved to the concept of a transformed scientific practice, shifting the focus of researchers' activity from 'publishing as fast as possible' to 'sharing knowledge as early as possible'.

Michael Nielsen's book 'Reinventing Discovery: The New Era of Networked Science' is arguably the first and most comprehensive coverage of Open Scholarship accessible to a broad readership. Michael Nielsen advocated Open Science as 'the idea that scientific knowledge of all kinds should be openly shared as early as is practical in the discovery process'.

The ecosystem underpinning open scholarship is evolving very rapidly. Social network platforms for researchers, such as Research Gate or Academia already attract many millions of users and are being used to begin and validate more research projects in a brain-sourced way. Open scholarship is extended to open forms of using code, scientific discovery and analysis, open research assessment and review, as well as outreach.

Open scholarship is predominantly the result of a bottom-up process driven by a growing number of researchers, who increasingly employ social media and a variety of digital means for their research to initiate globally coordinated research projects and share results at an early stage in the research process, for example through electronic notebooks that allow for realtime global sharing of 'raw' research data among collaborating partners and facilitate access to results for potential collaborators.

An early and well-known example of open scholarship from the pre-internet stage is the Human Genome Project that started in 1990. The data on the human genome was widely shared among the scientific community in the course of the project, while at the same time a moratorium on publishing was kept in order to encourage optimal collaboration. Because of this openness, they were able to decode the human genome in less than 15 years. Open scholarship has shifted the prime focus of researchers away from publishing towards knowledge sharing.

The ongoing changes are progressively transforming scientific practices and innovative tools to facilitate communication, collaboration, and data analysis are appearing. Researchers increasingly work together to create knowledge. Online tools create a shared space where creative conversation can be scaled up. As a result, the problem-solving process can be faster and the range of problems that can be solved can be expanded (Nielsen 2012). 
Fuelled by the new opportunities for knowledge and data-sharing, more open practices have emerged to address pressing issues at an early stage. For example, five months into the largest Ebola outbreak in history, an international group of researchers sequenced three viral genomes, sampled from patients in Guinea. The data was made public that same month This open scientific practice was extended into making experimental vaccine available within a short period and proved vital in combatting relatively smaller outbreaks in 2018. The National Institutes of Health in the United States now require grantees to make large scale genomic data public by the time of publication at the latest. The World Health Organisation (WHO, 2015) seeks a paradigm shift in the approach to information sharing in public health emergencies, from one limited by embargoes set for publication timelines, to open sharing using modern fit-for-purpose pre-publication platforms. Researchers, journals and funders will need to engage fully for this paradigm shift to occur. The WHO acknowledged that patents on natural genome sequences could be inhibitory for further research and product development and wants research entities to exercise discretion in patenting and licensing genome-related inventions so as not to inhibit product development and to ensure appropriate benefit sharing. The organisation also wants scientific publishers not to penalize, but to encourage or mandate public sharing of relevant data. Zikka was the next major emerging public health issue that was tackled with effective initiatives based on open scholarship.

The way the WHO dealt with these public health issues and the associated commendable initiatives of researchers who obviously felt a moral obligation to engage in open scholarship practices with a view on the urgency of the matter deserve to become a model for scientific practice as such. However, this practice is currently more an exception than the rule.

\section{Reproducibility and productivity crises in science}

Open scholarship strongly contrasts with mainstream science, which has become too competitive in nature and often mandated by major industries. This has led to the serious situation that 'Science goes wrong'. The magazine the Economist noted in a lead article of October 2013:

Too many of the findings that fill the academic ether are the result of shoddy experiments or poor analysis. A rule of thumb among biotechnology venture-capitalists is that half of published research cannot be replicated. Even that may be optimistic. Last year researchers at one biotech firm, Amgen, found they could reproduce just six of 53 "landmark" studies in cancer research. Earlier, a group at Bayer, a drug company, managed to repeat just a quarter of 67 similarly important papers. A leading computer scientist frets that three-quarters of papers in his subfield are bunk. In 2000-10 roughly 80,000 patients took part in clinical trials based on research that was later retracted because of mistakes or improprieties.

Competitive science operates in a closed context whereby researchers and innovators anxiously seek to protect research results and intellectual property rights. It is from this point of view not surprising that research data that are published or produced in the context of clinical trials are not reliable. Science only goes 'well' when scientists rigorously verify their data with often painful repetitions of research efforts for which there is neither time nor willingness to share data with other colleagues in the context of competitive science.

Nature (May, 26, 2016) asked 1,576 scientists for their thoughts on reproducibility. Most agree that there's a 'reproducibility crisis' and over $70 \%$ said they'd tried and failed to reproduce another group's experiments. This crisis is certainly not only due to the competitiveness of science as such, yet it constitutes a problematic constellation with other 
'methodological factors such a publication bias towards statistically significant results or the very context dependent use of samples in research'. Manufo et al (2017) offer a comprehensive overview.

Research productivity of scientists is most often measured by bibliometric means. The (ab)use of journal impact factors is at the heart of the dispute here. It is a measure reflecting the average number of citations to articles published in an academic journal over a period. It is used as a proxy for the relative importance of a journal and as a surrogate for scientific quality, with articles in high impact journals considered to be of high quality regardless of how many citations they receive individually. Numerous criticisms have been made of citation-based metrics, especially when (mis)used to assess the performance of individual researchers: often they are not applicable at the individual level; they do not take into account the broader social and economic function of scientific research; they are not adapted to the increased scale of research; and they cannot recognize new types of work that researchers need to perform. The practice persists even though even prominent researchers, e.g. Nobel Prize winners have turned their back to this de-railed form of rewarding scientific outputs (Nobel Prize winner Randy Schekman called for a boycott of journals with high impact factors like Science, Nature and Cell in December 2013).

The most important element here may not be the inappropriate way of 'measuring' quality, but the incentives it creates for scientists to become 'productive' by producing as many papers as possible and engaging in a time-consuming article submission process with a high risk for rejection. Nature (editorial lead of December 2006) reported that

Nature receives approximately 10,000 papers every year and our editors reject about $60 \%$ of them without review. (Since the journal's launch in 1869, Nature's editors have been the only arbiters of what it publishes.) The papers that survive beyond that initial threshold of editorial interest are submitted to our traditional process of assessment, in which two or more referees chosen by the editors are asked to comment anonymously and confidentially. Editors then consider the comments and proceed with rejection, encouragement or acceptance. In the end we publish about $7 \%$ of our submissions.

The reproducibility crisis comes together with a 'productivity' crisis equally linked to an increasingly competitive closed science. Research efforts have increased exponentially during decades whereas research productivity has dropped dramatically. Bloom et al (2017) found that 'since the1930s, research effort has risen by a factor of 23 - an average growth rate of 4.3 percent per year'. However, research productivity has fallen: 'by a factor of 41 (or at an average growth rate of -5.1 percent per year') (Bloom et al, 2017, page 7). The authors generated robust findings that research productivity is falling sharply everywhere they looked (agriculture, medicines etc) despite an exponential increase of research efforts. 'Taking the U.S. aggregate number as representative, research productivity falls in half every 13 years ideas are getting harder and harder to find. Put differently, just to sustain constant growth in GDP per person, the U.S. must double the amount of research effort searching for new ideas every 13 years to offset the increased difficulty of finding new ideas' (Bloom et al, 2017207, p.46) 
The decline in pharmaceutical Research and Development efficiency is dramatic: The number of drugs approved by the US Food and Drug Administration (FDA) per US dollars(inflationadjusted) spent on R\&D has halved roughly every 9 years since 1950 (Bountra et al, 2017).

There are multiple factors responsible for the decline in productivity. However, the consequences of careerism in science may well play a role here. The incentives for scientists to make a career lie predominantly in the publication of research papers in high-impact journals. These journals are biased towards articles that raise interest in the research community itself rather than contributing to, for example, the actual improvement of treatment of patients (this concerns the cited 60 percent rejection rate of without review, which concerns the editorial interests in the subject matter rather than scientific quality or relevance).

For scientists, publishing activities take precedence over delivering on societal relevance, and science has become self-referential: Science is assessed based on excellence, a criterion on which only scientists themselves decide, and used as an effective argument to keep societal interests out of the equation in defense of the 'autonomy' of science and their institutions (Holbrook, 2017). 'Excellence' driven science is funded under very competitive funding systems and scientists spend a large amount of their time on submitting proposals for doing 'excellent' research rather than executing research. Johan Bollen (2018) rightly noted that the European University Association in 2016 estimated that the equivalent of at least one-quarter of Europe's Horizon 2020 funding programme goes to preparing grant applications (see go.nature.com/2vx3mjx). A 2013 study estimated that Australian scientists collectively spent more than five centuries of time preparing 3,727 proposals in 2012 (Herbert et al, 2013).

What would happen if all these scientists instead of spending the (centuries!) of time of competing for grants, openly collaborated on research topics of common societal interest? Johan Bollen (2018) developed a Self-Organizing Funding Allocation system that would do away with all these time-consuming submissions for research grants and would guarantee research professors a basic research budget, which could be increased or decreased by anonymous donations to other research professors whose research they find worthy of support. Simulations of his model showed that the total costs for the alternative funding would remain the same if each research professor were allocated 160000 Euro; yet, obviously, research efforts and the productivity of the scientific system would benefit dramatically. Early 2018, the Netherlands Organization for Scientific Research held a workshop to plan a pilot test with this alternative funding system, after the Dutch Parliament directed it to explore alternative modes of funding. This alternative may need some fine-tuning, but it demonstrates how the current competitive funding systems contributes to an unproductive scientific system. The current rewards and incentives system for scientist and the associated use of metrics chase researchers on their 'research productivity'. This results in a paradox of scientific productivity. The more individual scientists become productive (in terms of the current system), the less productive the scientific system becomes in terms of delivering on societally relevant and desirable outputs.

\section{The rationale of open research and scholarship}

It is clear that the current reputation and evaluation system has to adapt to the new dynamics of open scholarship and acknowledge and incentivise engagement with open research activities. The rationale has to shift from publishing as fast as possible to sharing knowledge 
as early as possible. Researchers have growing expectations that their work, including intermediate products such as research data, will be better rewarded or considered in their career development. In the light of an ever more data-intensive science whereby scientific progress is dependent on effective data sharing for the completion of scientific missions, the primary focus on publishing articles seems antiquated. Excellent science is also seldom a matter of individual intellectual superiority rewarded by competitive funding systems, but increasingly more a matter of excellent collaboration among a great number of scientists. The article in which empirical evidence was revealed for the existence of gravitational waves conjectured 100 years ago by Einstein was written by 1000 authors. The 502nd co-author of this article was probably less involved in the overall design and organization of the research as the first few authors, but they were probably quite essential for the completion of this research. Research is increasingly also networked and collaborative by necessity.

Edwards (Edwards et al. 2011) noted that researcher interest has favored a small fraction of human protein kinases of the total relevant human protein kinases in the search for new molecules that could contribute to combatting disease for many decades, reflecting major industry interests (research has concentrated on fewer than 50 of the 500 known kinases). Competitive science narrows societal relevance to set of possibilities with anticipated economically exploitable results. Hence, the productivity and reproducibility crises linked to a competitive closed form of science constitute an obstacle for responsible societally relevant outputs of science.

Currently we are dependent on courageous initiatives such as those from Miedema et al at the Utrecht Medical Centre, who are running a pilot with an alternative reward and incentive system for research professors who must have their research assessed by a broad set of stakeholders, including patient organizations and industry (Miedema, 2018).

Open research activities as conducted by the Structural Genomics Consortium (SGC), a nonfor-profit organization, widen the scope of societally relevant research. The SGC's mission is to catalyze research in new areas of human biology and drug discovery by focusing explicitly on less well-studied areas of the human genome, ignored by industry. SGC's mission statement reads ${ }^{2}$ :

'The SGC accelerates research in these new areas by making all its research output available to the scientific community with no strings attached, and by creating an open collaborative network of scientists in hundreds of universities around the world and in nine global pharmaceutical companies'.

Together, this network of academic and industry scientists is driving a new scientific and drug discovery ecosystem whose primary aim is to advance science and is less influenced by personal, institutional or commercial gain.

The SGC collaborates within a global network of researchers who refrain from applying intellectual property rights in the research, discovery and exploration phase and who share data through open notebooks, thereby creating a creative commons. Intellectual property rights (IPR) still play a role in the commercial process of actual drug-development, but the refraining from IPR in the research, discovery and exploration phase avoids the inhibition of the innovation process. They have established a public-private partnership with 8 industries. The results are impressive: The SGC started in 2004 and outcomes to date include more than 25 ongoing clinical trials, while significantly reducing the time lime of bringing molecules to clinical trials. 
Following the mission philosophy of the SGC, open, collaborative, networked research already provides a rationale for responsible, open innovation. First, one must realize that to yield the 'right societal impacts' of research, the quality of the scientific base must provide for it. Surely an ineffective science will have societal impacts, yet their societal quality and scope will be contestable. Opening research systems and facilitating pro-active data sharing (prior to publishing), open verification and review as well as the publication of unsexy products of science, such a 'negative' results, will improve the quality of the science base and therefore can provide a better direction to possible innovation outputs. Open, collaborative research systems will make science more efficient as we can share resources and avoid the unnecessary duplication of research work, and more reliable because of better collective verification. Open research systems and open scholarship will overcome the productivity crisis in science. The current system incentivizes scientists to become ever more productive by producing more publications. However, although engaging massively with competitive science, either in 'excellence' driven research funding contexts or in competitive mandated research projects funded by industry, the scientific system as such becomes more unproductive.

Open research and scholarship ${ }^{3}$. not only relates to the openness of 'knowledge sources', such as data or publications, but also to the openness (and responsiveness) of the knowledge actors towards each other: Open research implies the involvement of all relevant knowledge actors in co-production mode, far beyond the conventional academic realm and might include citizen scientists.

Innovations are brought about by coalitions of academics, industrialists and societal actors, including an increasing body of citizen science. These knowledge coalitions will make it possible to direct and re-direct science to deliver on innovations that are societally beneficial. 


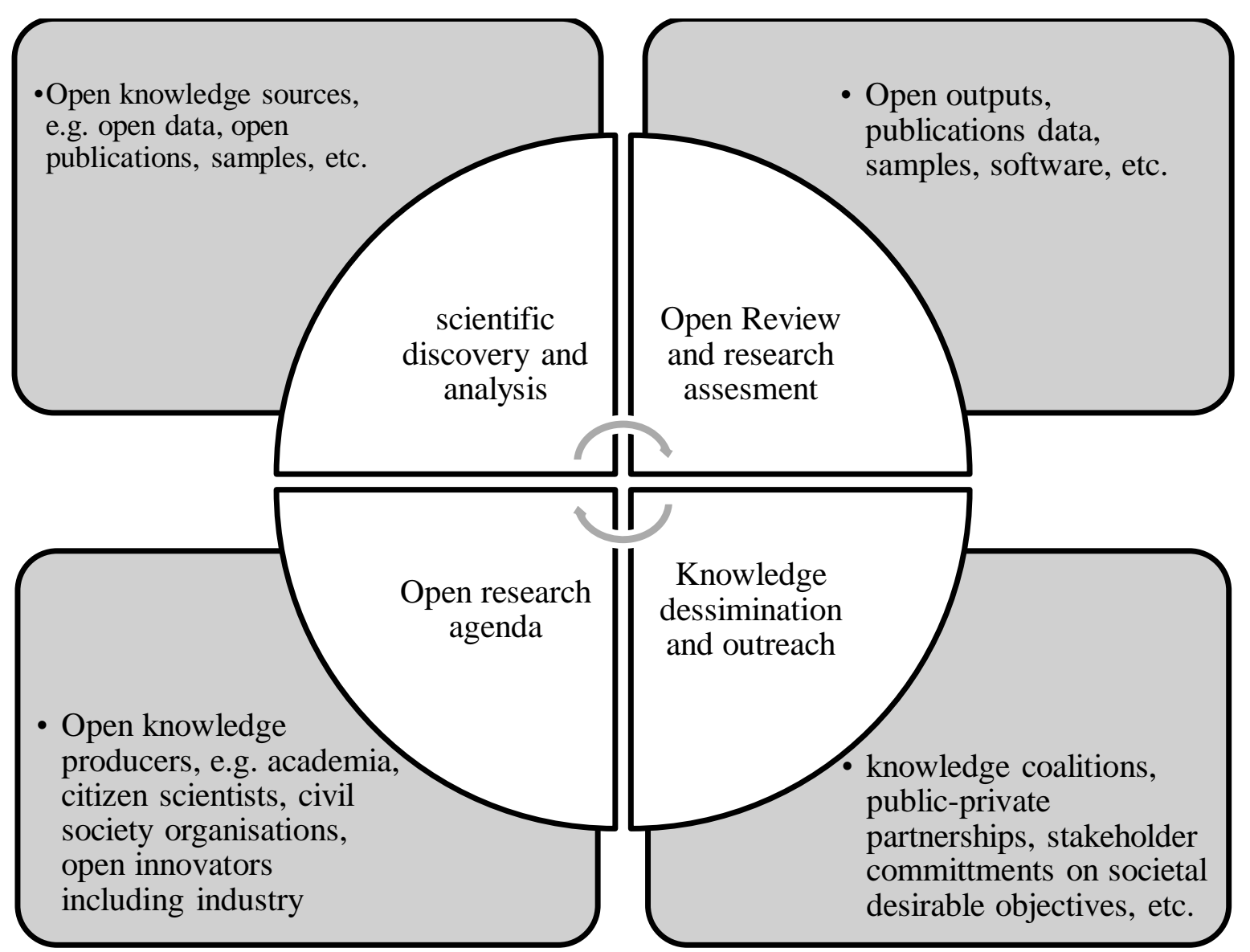

A full cycle of open research and scholarship starts with open research, set through the mutual openness of knowledge actors (towards each other) in defining the research agenda following the input of the issue-relevant open knowledge inputs These reflect the phases of the usual research cycle of research agenda setting and the corresponding process of research discovery and analysis. So, the left half of the cycle represent the open research and scholarship inputs, both in terms of knowledge actors and knowledge sources.

The right half of the cycle represents Open Research and Scholarship outputs, both in terms of knowledge outputs (publication, data etc.) and actual outputs of coalitions of knowledge actors. These come about as the results and validated output from open review and assessment, equally resulting in effective knowledge coalitions collaborating in outreach and knowledge dissemination. Open knowledge sharing is an element present at all stages of the research process, from agenda setting to the dissemination of (validated) knowledge. 
Open research and scholarship can be defined as:

'sharing knowledge and data as early as possible in the research process in open collaboration with all relevant knowledge actors'.

Thus, the example of the rationale of doing open research as, for example, practiced by the SGC already resembles a model of responsible innovation without any apparent strong normative requirements embedded in formal research policies. However, it must be said that here the researchers themselves took the normative choice to address diseases ignored by industry and thereby took the perspective of responsible innovation, with an effort to deliver on societally desirable outputs while compensating (with a public-private partnership) for existing serious market-deficits.

\section{Interdependence of open research and open innovation}

The SGC example demonstrates the immediate interdependence of open research and open innovation. However, it is important here to understand the distinct features of the incremental steps required to go from credible research, to responsive research and responsible research in the research dimension and the distinct features of credible innovation, responsive innovation and responsible innovation. First, the creation of knowledge in science underlies distinct universalizable codes for 'good' research conduct, enabling a global research practice that is virtually independent of cultural and national constraints. As the previous director of the US National Science Foundation Subra Suresh put it: 'Good science anywhere is good for science everywhere'. To find an equivalent for this statement for 'innovation' is an intellectually interesting endeavor, yet it will not yield a result with an equal level of universalizability as for the science dimension. One may propose: Good innovation anywhere, might be beneficial for many, somewhere. The latter reflects that innovation outcomes may be successful in particular cultures and nations while at the same time they may have a global reach as well. The somewhere is important here for the allocation of the impacts of research and innovation. It must create problems even for the classical advocates of innovation with a view on 'jobs and growth'. Apple, arguably one of the most innovative companies of the last decade, did not create the 'impacts' where they were wanted. Steve Jobs famously replied to President Obama's question what it would take to make iPhones in the United States? 'Those jobs aren't coming back' (Politico, 2012). Responsible innovation transcends and relativizes the 'somewhere' since responsible innovation seeks to address societally desirable outcomes beyond national contexts.

Second, the step-up processes show, respectively, the incremental steps with their criteria towards responsible research and responsible innovation. The criteria listed for each step are to be understood as additional criteria in comparison to the previous step: obviously responsible science presupposes credible and responsive science. 
Figure 2: Step-up process for 'good' open research with additional criteria for each step

Credible reseach:

Standards of scientific integrity, codes for good research conduct
Responsive research: open, collaborative and networked science
Responsible research: anticipatory on outcomes and impacts

Figure 3: Step-up process for 'good' open innovation with additional criteria for each step

Credible innovation: international standards, codes of conduct, ethical guidelines
Responsive innovation: open innovation with broadly composed knowledge coalitions
Responsible innovation: mutual responsiveness among stakeholders with a normative commitment to address a societal desirable objective(s)

The sixth point of departure for a vision of responsible innovation concerns the call for rewarding and establishing open, collaborative research and scholarship practices. Open research and scholarship are a necessary but not sufficient condition for responsible innovation. Open research and scholarship already provide for better opportunities and a broader scope for societal relevance but does not yet meet all conditions to drive innovations towards societally desirable ends. For that, we must turn to a sixth deficit.

\section{Sixth Deficit: Lack of Foresight and Anticipative Governance for the alternative shaping of innovation in sectors.}

Although open research and scholarship provide for responsiveness towards societal demands and broadens the scope for actually addressing societal desirable options, it does not yet provide the sufficient conditions to steer research and innovations or to complete missionoriented research towards these goals. I expressed the call for the establishment of 
professional bodies that would look into the type of outcomes we want to get out of research and innovation processes, and the establishment of governance mechanisms that would give some direction to the innovation process under the first section.

To bring this forward, I believe the institutionalisation of foresight, public-private partnerships based on governance mechanisms such as codes of conduct, coupled with various mechanisms for impact assessment, should pave the way for a better governance of emerging technologies and make them productive in delivering on societally desirable outcomes.

Foresight is necessary to facilitate the possibility to 'shape' technologies and provide for better governance. To illustrate this point, I turn to the example of precision agriculture.

Precision agriculture makes use of a variety of monitoring -technologies, involving, among other things drones used for the mapping of weeds, alongside other GPS enabled technologies that monitor very local weather and soil conditions. Unmanned tractors equipped with sensors can provide information for specific crop management in terms of water and pesticide use. 'Texting' cattle can provide information on their (health) condition.

Precision Agriculture will further rationalise the agriculture and food system of the future as it promises to increase the capacity for coping with environmental pressures, to increase the quality of the agricultural outputs, all while reducing costs and to enhance food safety. The future of farming can follow quite different scenarios, depending on among other things which business models will prevail, the extent to which public authorities intervene and the socio-economic model driving farming businesses. A crucial factor will be the decision on whether the data gathered by precision agriculture techniques will be owned by big companies or remain publicly accessible or owned by the farmers.

The implementation of Precision Agriculture can follow different scenarios. A scenario of large scale farming concentrating on the production of commodity crops such as soya and maize, enabled by unmanned farms, remotely monitored in the management offices of big agribusinesses, is as equally as possible as a scenario in which a variety of farm scales coexists with farmers who share the data among themselves and who jointly facilitate the direct sales of crops to local markets via online shops.

The following table gives a sketch of the possibilities ranging between options for an approach enabling responsible innovation or a fully market-driven innovation approach guided without public interference.

Table 1: The alternative shaping of precision agriculture technologies by a responsible innovation approach or a global-market driven approach respectively

\begin{tabular}{|l|l|l|}
\hline $\begin{array}{l}\text { Factors for 'shaping' the } \\
\text { technology }\end{array}$ & 'Responsible Innovation' & $\begin{array}{l}\text { Global-market driven } \\
\text { innovation }\end{array}$ \\
\hline Stakeholder involvement & Involving all producers/users & $\begin{array}{l}\text { Technology push by big } \\
\text { agribusiness }\end{array}$ \\
\hline Societal objective & $\begin{array}{l}\text { Determined by common } \\
\text { stakeholder commitments }\end{array}$ & $\begin{array}{l}\text { Technology and market- } \\
\text { efficiency driven }\end{array}$ \\
\hline Overall-technology design & $\begin{array}{l}\text { Normative design with } \\
\text { determining factors such as } \\
\text { data ownership, scale of use, }\end{array}$ & $\begin{array}{l}\text { Fragmentary, sequential } \\
\text { technology introduction } \\
\text { whenever they become } \\
\text { available }\end{array}$ \\
\hline
\end{tabular}




\begin{tabular}{|c|c|c|}
\hline & $\begin{array}{l}\text { privacy by design } \\
\text { approaches etc. }\end{array}$ & \\
\hline Access to resources & $\begin{array}{l}\text { Public authorities enabling } \\
\text { access to resources including } \\
\text { to small farmers }\end{array}$ & $\begin{array}{l}\text { Resource access inequalities } \\
\text { remain unaddressed }\end{array}$ \\
\hline Data- access and ownership & Data ownership with farmers & $\begin{array}{l}\text { Data ownership primarily } \\
\text { with big agribusinesses }\end{array}$ \\
\hline Economic policy & $\begin{array}{l}\text { Aligned to socio-economic } \\
\text { needs, business models } \\
\text { based on sharing of data }\end{array}$ & $\begin{array}{l}\text { Business models based on } \\
\text { centralised data systems in } \\
\text { big agri-businesses, early } \\
\text { technological fixes }\end{array}$ \\
\hline Governance & $\begin{array}{l}\text { Codes of Conduct, Public- } \\
\text { Private Partnerships }\end{array}$ & Global markets driven \\
\hline
\end{tabular}

A proper foresight exercise provides enormous insights in the diversity of options. Normally, these options escape the attention of the public, and to some extent, the attention of policy makers. The study 'Precision agriculture and the future of farming in Europe, Scientific Foresight Study' facilitated by the Scientific and Technological Options of the European Parliament (2016) was an interesting initiative whose aim was to anticipate the governance issues ahead of us at an early stage.

This particular study provided an overview of plausible governance issues depending on which type of global socio-economic scenarios would prevail. The study also suggests a new forward-looking typography of what new farming business could be, including the following new professional profiles (page 34):

The Geo-Engineer would specialise in carbon sequestration, alongside a food production business...

The Energy Farmer would specialise in renewable energy production and management for the local area...

The Web Farm Host would... give a constant, positive commentary to the outside world, explaining what is going on and often giving virtual tours to school children...

The Animal Therapist would act as a welfare manager for farm animals ... making sure that consumers buying meat or dairy products from the farm are able to access information about animal wellbeing...

The Pharmer would use biotechnology expertise to grow and harvest plants that have been genetically engineered with foreign DNA to make them produce medicine...

The Insect Farmer would farm large quantities of insects for use as natural predators to control the new species of insect that spread in farming areas because of climate change

This list shows the necessity for policy guidance and intervention as well as public deliberation. Only if this type of deliberation is executed will a meaningful democratic direction be imparted to the innovation process. Otherwise possible options will have disappeared over time, without anyone realizing that it had previously been an actual 'shaping' option. Ideally, foresight practices need to be combined with impact assessments for the various future options and scenarios. It is important here to underline that those 
assessments should not 'evaluate' the technological option as such, but rather the socioeconomic impacts of the changes a 'set of technologies' such precision agriculture technologies will make to the system as a whole. In the case of precision agriculture, the impact assessments should therefore concentrate on the agri-food system as a whole. This makes the alignment with broad public values and expectations regarding the sector equally possible. Such impact assessments could thus include vision assessments including those from a wider public (See Grunwald, 2018 for excellent overview on Technology Assessment).

There is an important role for the ethics of normative design of systems and technologies. Ethics has to move beyond an ethics of constraints (e.g. focussing on what should prohibited or limited) to an ethics of construction. Normative design in open interaction with users is already practiced in ICT and should now be extended to the sectors in which they will operate. Codes of conduct embraced by both public authorities and the private sector are also important. Codes of conduct have the advantage over legislative action since they can already be operational in a context where the technology is still in development and can equally steer its direction by facilitating proper self-regulation and enabling and assigning responsibilities to all stakeholders.

To stay with the example of Precision Agriculture: In early 2018 a coalition of associations from the EU agri-food chain launched in early 2018 a joint EU Code of Conduct on agricultural data sharing. The Code promotes the benefits of sharing data and implies dataownership with farmers whenever they are at the origin for the generation of those data. ${ }^{4}$

In a similar vein, the normative design of artificial intelligence technologies was discussed for the first time in the European Parliament in November 2018. The Atomium European Institute for Science, Media and Democracy initiated a discussion on 'what is a good AI society', proposing a framework in which artificial intelligence is constructed as a technology that can enable human self-realisation, enhance human agency, increase societal capabilities and cultivate societal cohesion (Atomium European Institute for Science Media and Democracy, 2018).

Meaningful foresight, normative design of technologies, and impact assessment can thus address the 'right impacts' or the positive outcomes of research and innovation. Marketdeficits can be identified and overcome with public investment and policy. Specific sectorsystem (agriculture, energy, mobility etc) alignment with public values and expectations can be facilitated by foresight and public deliberation. Societally desirable outputs can take precedence over technological potential while open research and scholarship can provide for insight and options for societally desirable innovations.

\section{Notes}

${ }^{1}$ René von Schomberg is based at the Directorate General for Research and Innovation of the European Commission. The views expressed here are those of the author and may not in any circumstances be regarded as stating an official position of the European Commission.

2 https://www.thesgc.org/

${ }^{3}$ National and European policy development for 'open science' has up till now notably be conceptualized for making the outputs of science more open: e.g. policies to require open access to scientific publications and open access to data. See for an outline of the vision of Commissioner Moedas on Open Science: Open Innovation, Open Science and Open to the World. Publication Office of the European Union, 2015. The proposal of the European Commission for the new European Framework Programme for Research and Innovation, Horizon Europe (2021-2027) may start with including policies to address the open inputs for science: societal challenges will be addressed under this programme with mission-oriented research and co-design of stakeholders. I prefer to use the term 'open scholarship and open research systems' to reflect the inclusion of the humanities in the equation as well as emphasizing the open input side to science, in the form of open collaboration and active data 
and knowledge sharing prior to publishing and other scientific open outputs. In the United States, the National Academy of Sciences issued a report embracing 'open science' in 2018: Open Science by Design, Realising a Vision for $21^{\text {st }}$ Century Research, National Academy Press, 2018

${ }^{4}$ See for full text, accessed 20/11/2018 at

https://www.copacogeca.eu/img/user/files/EU\%20CODE/EU_Code_2018_web_version.pdf

\section{References}

Atomium European Institute for Science Media and Democracy (2018), accessed 20/11/2018 at http://www.eismd.eu/ai4people/

Baker, Dean, Arjun Jayadev and Joseph Stiglitz (2017), 'Innovation, Intellectual Property Right and Innovation. A better set of approaches for the $21^{\text {st }}$ Century', accessed 20/11/2018 at http://ip-unit.org/wp-content/uploads/2017/07/IP-for-21st-Century-EN.pdf

Bessen, James and Michael Meurer (2014), The Direct Costs from NPE Disputes. 99 Cornell L. Rev. 387 (2014) Boston Univ. School of Law, Law and Economics Research Paper No. 1234.

Bloom, Nicholas, Charles Jones, John Van Reenen and Micheal Web (2017), 'Are ideas getting harder to find?', accessed 20/11/2018 at https://web.stanford.edu/ chadj/IdeaPF.pdf

Bollen, Johan (2018), Who would you share your funding with?, Nature, vol 560, 9 August 2018

Bountra, Chas; When Wha, Lee and Javier Lezaun (2017), A new pharmaceutical commons: Transforming Drug Discovery, Oxford Martin Policy Paper, Oxford Martin School

Dosi, G. and J. E. Stiglitz (2014), The Role of Intellectual Property Rights in the Development Process, with Some Lessons from Developed Countries: An Introduction. In Intellectual Property Rights: Legal and Economic Challenges for Development, Mario Cimoli, Giovanni Dosi, Keith E. Maskus, Ruth L. Okediji, Jerome H. Reichman, and Joseph E. Stiglitz (eds.), Oxford, UK and New York: Oxford University Press, pp. 1-53.

Economist, Science goes Wrong, lead article, October 2013

Edwards, Aled, Ruth Isserlin, Gary D Bader, Stephen V. Frye, Timothy M Willson, and Frank H Yu (2011), Too many roads not taken, Nature, vol 470, p 163-165

Evers, Albert and Helga Nowotny (1987) Uber den Umgang mit Unsicherheit, Frankfurt am Main: Suhrkamp Verlag.

Commission of the European Communities (2001), European Governance: A White paper, 25 January 2001

Commission of the European Communities (2004) Communication from the commission to the council, the European Parliament and the European Economic and Social Committee. Nanosciences and Nanotechnologies: An action plan for Europe 2005-2009. Second Implementation Report 2007-2009, Brussels, 29.10.2009, COM (2009) 607 final (citation on page 10).

Commission of the European Communities (2011), Europe 2020 Flagship Initiative Innovation Union, Communication to the European Parliament, the Council, the European Economic Committee, and the Committee of the Regions. SEC(2010) 1161 
European Commission (2015) Open Innovation, Open Science and Open to the World. Publication Office of the European Union, 2015.

Fisher, Erik, Roop L. Mahajan and Carl Mitcham (2006). "Midstream Modulation of Technology: Governance from Within.” Bulletin of Science, Technology \& Society 26(6): 485- 496.

Grunwald, Armin (2018). Technology Asssessment in Practice and Theory, Routledge

Herbert, D. L. (2013) A. G. Barnett and N. Graves Nature 495, 314; 2013

Holbrook, J. Britt. (2017). "Peer Review, Interdisciplinarity, and Serendipity" in The Oxford Handbook of Interdisciplinarity, $2^{\text {nd }}$ edition. Robert Frodeman, Julie Thompson Klein, Roberto C. S. Pacheco, eds. Oxford: Oxford University Press, pp. 485-97.

Karinen, Risto and David H Guston (2010) "Towards Anticipatory Governance. The Experience with Nanotechnology". In: Governing Future Technologies. Nanotechnology and the Rise of an Assessment Regime. Mario Kaiser (eds). Springer: Dordrecht, Heidelberg, London, New York, page 217ff.

Lund Declaration (2009). Conference: New Worlds - New Solutions. Research and Innovation as a Basis for Developing Europe in a Global Context. Lund, Sweden, 7-8 July 2009, accessed 20/11/2018 at http://www.se2009.eu/polopoly_fs/1.8460!menu/standard/file/lund_declaration_final_version _9_july.pdf|http://www.se2009.eu/polopoly_fs/1.8460!menu/standard/file/lund_declaration_fi nal_version_9_july.pdf

Miedema, Frank (2018). Setting the Agenda. Who are we answering to? Blog, BMJ Open Science, posted on 24 January 2018, accessed 20/11/2018 at https://blogs.bmj.com/openscience/2018/01/24/setting-the-agenda-who-are-we-answering-to/

Munafò, M. R., B.A. Nosek, D.V.M. Bishop, K.S. Button, C.D. Chambers, N. Percie du Sert and J.P.A. Ioannidis (2017). A manifesto for reproducible science. Nature Human Behaviour, 1, 21. accessed 20/11/2018 at https://doi.org/10.1038/s41562-016-0021

National Academies of Sciences (2018) Open Science by Design, Realizing a Vision for $21{ }^{\text {st }}$ Century Research, National Academy Press, 2018

National Nanotechnology Initiative (2001), accessed 20/11/2018 at http://nano.gov/aboutnni/what/vision-goals

Nature (2006), editorial lead of December 2006, doi:10.1038/nature05535

Nielsen, Michael (2013), Reinventing Discovery: The New Era of Networked Science, Princeton University Press. 
Politico (2012), 'Obama sparred with Steve Jobs over outsourcing' Politico44blog, accessed 20/11/2018 at https://www.politico.com/blogs/politico44/2012/01/obama-sparred-with-stevejobs-over-outsourcing-111751

Urgenda (2018), The Urgenda Climate Case against the Dutch Government, accessed 20/11/2018 at https://www.urgenda.nl/en/themas/climate-case/

Stahl, Bernd Carsten (2011): "IT for a Better Future: How to Integrate Ethics, Politics and Innovation" In: Journal of Information, Communication and Ethics in Society (9:3), Special Issue on Emerging Technology and Ethics, edited by Kutoma Wakunuma, 140-156

Stilgoe, Jack (2014) Against Excellence, Guardian, 19 December 2014

Scientific and Technological Options of the European Parliament (2016), Precision agriculture and the future of farming in Europe, a scientific foresight study, accessed $20 / 11 / 2018$ at

http://www.europarl.europa.eu/RegData/etudes/STUD/2016/581892/EPRS_STU(2016)58189 2_EN.pdf)

Ozolina, Zaneta, Carl Mitcham, Doris Schroeder, Emilio Mordini, Paul McCarthy and John Crowley (2012), Ethical and Regulatory Challenges to Science and Research Policy at the Global Level

Owen, Richard, Jack Stilgoe, Phil MacNaghten(2013). A Framework for Responsible Innovation in: R. Owen, M. Heintz and J Bessant (eds.) Responsible Innovation. London: John Wiley

Von Schomberg, Rene (2007), From the ethics of technology towards and ethics of knowledge policy. Working document of the Service of the European Commission. Luxembourg: Publication Office of the European Union, accessed 20/11/2018 at http://renevonschomberg.wordpress.com/organising-collective-responsibility-ethics-ofcoresponsibility/

Von Schomberg, Rene (2013), "A vision of responsible innovation". In: R. Owen, M. Heintz and J. Bessant (eds.) Responsible Innovation. Managing the Responsible Emergence of Science and Innovation in Society. London: John Wiley 